\title{
Severe Acute Respiratory Syndrome Coronavirus 2 (SARS-CoV-2) and Coronavirus Disease-2019 (COVID-19): A Review
}

\author{
Tejas R. Suthar ${ }^{1}$, Sandip T. Gaikwad ${ }^{1 *}$ and Abhinn D. Suthar ${ }^{2}$ \\ ${ }^{1}$ MIT College of Food Technology, MIT ADT University, Pune, India \\ ${ }^{2}$ MIT School of Bioengineering Science \& Research, Pune, India \\ *Corresponding author
}

Keywords

Coronavirus,

Outbreak Reality,

Symptoms,

Precautions,

Ayurveda Role

Article Info

Accepted:

30 March 2020

Available Online:

10 April 2020

A B S T R A C T

COVID-19 is an acute respiratory diseases that caused by the virus called coronavirus and has gained worldwide attention in very short time. Coronaviruses are large family of viruses that covering people and many different species of animals including cats and bats. An acute respiratory disease caused by a novel coronavirus (SARS-CoV-2, formerly known as 2019-nCoV), the 2019 coronavirus disease (COVID-19) has spread and gained worldwide recognition. This coronavirus, was initially identified by the World Health Organization (WHO) as the 2019-novel coronavirus (2019-nCoV) on 12 January 2020. This article tries to comprehend the basic information regarding the COVID-19 with its history, symptoms and detection methods. This review also provides the global and Indian scenario till date with some preventive information in context of Ayurveda.

\section{Introduction}

Coronaviruses (CoV) are a broad family of viruses that cause diseases ranging from common cold to more serious diseases such as Middle East Respiratory Syndrome (MERS$\mathrm{CoV})$ and Extreme Acute Respiratory Syndrome (SARS-CoV). Coronavirus disease (COVID-19) is a new strain which was discovered in 2019 and has not been reported historically in human.

Coronaviruses (Fig. 1) are zoonotic which means that they are transmitted between animals and humans. Corona is a virus with single stranded RNA associated with a nucleoprotein and belongs to Coronaviridae family. Detailed studies showed that SARS$\mathrm{CoV}$ was being transmitted to humans from civet cats and MERS-CoV from dromedical camels to humans. Several known coronaviruses occur in animals not yet infected by humans. Respiratory symptoms, fever, cough, shortness of breath and trouble breathing are typical signs of infection. In more serious cases, pneumonia, extreme acute respiratory syndrome, kidney failure and even death may result from infection. The outbreak 
of corona virus (COVID - 19) started on 13th January in Wuhan Provence, China and has spread to the number of countries including India. Now this outbreak is not just an outbreak it's a pandemic. People can't follow their routines due to corona.

According to the WHO the infection of corona virus affects lungs in three phases;

Viral replication

Immune hyper-reactivity

Pulmonary destruction source

The target are of this virus is upper airways of lungs and can infect and divide in mucous producing pulmonary cells or ciliated cells (www.who.int).

\section{History}

Human coronaviruses, first characterized within the 1960s, are liable for a considerable proportion of upper tract infections in children. A total of 5 new human coronaviruses have been identified since 2003, including the extreme acute respiratory coronavirus syndrome, which caused substantial morbidity and mortality. There is been further division of new human coronavirus, out of those 5 three are group I viruses that are closely related and sure represent the identical viral species and other two are group II viruses (Kahn et al., 2005).This 5 type of new human coronaviruses are categorized according to name of virus, location, group and year which is shown in Table 1.

There were different number of research scientist had been involved in reporting this 5 kind of new coronavirus. In 2004, Van der Hoek et al., (2004) reported the discovery of new human corona virus NL63, isolated from girl who is 7 months old. Between December 2002 and April 2003, there is been 614 respiratory specimen collected out of which 7 turned to be positive for NL63.

Soon afterwards, Fouchier et al., (2004) identified coronavirus, called NL, isolated from an 8-month-old boy with pneumonia. Between November 2000 and January 2002, 4 respiratory specimen out of 139 reported positive for NL. The discovery of both NL63 and NL depended on the spread in cell culture of the viruses and this both viruses are belong to group I viruses.

Esper et al., (2017) find evidence of a human respiratory coronavirus, known as New Haven coronavirus ( $\mathrm{HCoV}-\mathrm{NH})$, in respiratory specimens collected from children under 5 years of age. Following the initial discovery of new HCoV-NH sequences, different samples were used to test respiratory specimens obtained from children under the age of 5 between January 2002 to February 2003 and it was reported that 79 out of 895 children tested positive for $\mathrm{HCoV}-\mathrm{NH}$.

It is not yet understood how HKU1 impacts but the manifestations of the disease associated with CoV-HKU1 include exacerbations of common cold, asthma, chronic obstructive pulmonary disease (COPD), and pneumonia. There were 832 adult respiratory specimen screened from which 13 showed positive for Cov-HKU1 (Esper et al., 2005). It can be justify that the coronaviruses that infect humans and cause respiratory disease are heterogeneous and distributed quite widely among groups I and II.

\section{Coronavirus (COVID-19) outbreak}

The origin of coronavirus is still a mystery. No evidence has been found indicating the origin of this coronavirus but it certainly originated from China. If we're talking about coronavirus outbreak then there's a lot of 
theories that have developed, some with facts and others don't.

First case of coronavirus occurred in China on November 17, 2019, this information was provided by Dr. Li Wenliang who was one of eight doctors who first raised the alarm about this coronavirus outbreak. He advised doctors to wear protective suits, as his hospital treated patients with an illness similar to SARS. Chinese police accused Dr. Li Wenliang of 'spreading rumors' after he posted warning on social media. Dr. Li Wenliang (34 year old) returned to work and later contracted the virus from the patients, on 30 January 2020 he was diagnosed with the coronavirus and died after a few days.

There are two key variants of the story and they have one common thread: that the coronavirus, SARS-CoV-2, originated in a research laboratory at level 4 (the highest level of biosafety) in Wuhan. In one version of the story, the virus was developed by humans as a bioweapon in the laboratory. In another version the virus was treated in the laboratory (after being isolated from animals) and then "escaped" or "leaked" because of poor safety protocols (Eliza Barclay, 2020).

It's also justified that the two books named "The Eyes of the Darkness" and "End of Days" predicted the coronavirus outbreak years ago!!!(Timesofindia.com, 2020)Suspense author Dean Koontz wrote about a virus named Wuhan-400 in a 1981 crimethriller book, titled 'The Eyes of The Darkness,' which was developed in a laboratory as a bio-weapon. The virus also had the capacity to wipe out a whole town or country. He wrote "It was around then that a Chinese scientist name Li Chen defected to the United States, carrying a diskette record of china's most important and dangerous-new biological weapon in a decade. They call the stuff 'Wuhan-400' because it was developed at their RDNA labs outside of the city of Wuhan, and it was the four-hundredth viable strain of man-made microorganisms created at that research center".

There is yet another book predicted the highly infectious coronavirus in the year 2008. Writer Sylvia Browne, wrote a book called "End of Days: Predictions and Prophecies on the End of the world." She wrote "In around 2020 several pneumonia- like illness will spread throughout the globe, attacking the lungs and bronchial tubes and resisting all known treatments. Almost more baffling then the illness itself will be the fact that it will suddenly vanish as quickly as it arrived, attack again 10 years later and then disappear completely".

\section{Symptoms of COVID-19}

The following symptoms may appear 2-14 days after exposure to corona virus (COVID19).

Dry cough

Shortness of breath

Fever

Headache

Gastroenteritis

Pneumonia

Nasal congestion

Runny nose

Sore throat

Fatigue

Bronchiolitis

Common cold

\section{Precaution of COVID-19}

The World Health Organization (WHO) have recommended simple precaution step to reduce exposure and transmission of coronavirus because there is no specific cure or vaccine yet detected for coronavirus. 
Wash your hands with soap and water regularly, or use a hand sanitizer based on the alcohol.

Avoid close contact with someone suffering fever or cough

When you cough or sneeze, cover your mouth and nose with the elbow or tissue

Avoid touching the head, nose and mouth unless your hands are clean

Evite near touch with someone is ill.

When you are sick, stop sharing of plates, cups, bedding, and other household items.

Clean and disinfect surfaces which you that encounter.

Stay home, if you're sick, from work, education, and public areas. Stop eating raw meat or animal organs, or undercooked.

\section{Detection methods for COVID-19}

There are mainly 4 detection methods are available to check weather an individual showing positive symptoms after being exposed to coronavirus (COVID-19).

\section{RT-qPCR}

A useful method for the in vitro detection of COVID-19 in respiratory specimens using RT-qPCR is the Assay Genie Coronavirus COVID-19 (SARS-CoV-2/ Strain 2019nCoV) One-Step RT-qPCR Detection package. PCR is an instrument used to determine the sum of genetic material (DNA or RNA) in a sample. This requires the use of an enzyme, normally Taq polymerase, which in cycles amplifies a brief particular portion of the template DNA.

A number of small, unique pieces of DNA are multiplied in each loop, resulting in exponential target amplification. The package also includes one set of primers and fluorescent probes to distinguish between SARS-CoV-2 and SARS-CoV (or SARSrelated $\mathrm{CoV}$ bat) and a positive control (PTC) and negative control (NTC) system. To demonstrate that the PCR amplification works efficiently with the supplied components, the positive control is provided. Every time the kit is used, a negative control reaction should be included to confirm the absence of contamination (Sarah Donovan, 2020).

\section{Immunofluorescence Assays}

The next approach used to detect viruses is immunofluorescence assays in a sample. It was commonly used to identify a number of viral antigens directly. It is possible to use infected cells such as those from the upper respiratory tract mucous membrane or cells that are found in the mucus aspirated from the nasopharynx. Immunofluorescence assays use a fluorescent label known as direct immunofluorescence or an antibody, known as indirect immunofluorescence, which is conjugated to the antiviral antibody. Look at the amount of fluorescence seen with UV light. The amount of an antibody binding to the antigen is directly associated with the amount of source produced by fluorescence (Sarah Donovan, 2020).

\section{Chest X-Ray}

Another method of screening for the presence of COVID-19 in a patient is a chest CT. Different characteristics associated with the presence of COVID-19 include ground glass opacities in the lungs caused by enhanced visibility of the lungs in which the vessels and bronchial structures can be seen.

Furthermore, lung alveoli can also be seen as interstitial thickening or partial collapse (Sarah Donovan, 2020).

\section{ELISA}

ELISA is the final tool for determining that a patient has been diagnosed with COVID-19. 
Antibodies or antigens can be identified in a sample by ELISA. If a patient has been diagnosed with SARS-CoV-2, viral antigens will be present which can be sampled and identified. Viral antigen-specific antibodies are attached to a plastic sheet, and the sample is overlaid. When the sample is positive for viral antigens, they bind to the antibodies unique to it. Before that is inserted a second antibody labelled with a marker. When the sample contains the viral antigens it will result in a positive reaction and when the correct substrate is applied, the marker will detect changing color. When there is no viral antigen present in the sample, the source does not change color. The SARS-CoV-2 antibodies which can be used in an ELISA detection kit include the spike antibody, the antibody shell, the membrane (Sarah Donovan, 2020).

\section{Role of ayurveda}

India is renowned for its ancient systems of medicine - Ayurveda, Siddha, and Unani. The Ayurvedic idea turned up and established in India between 2500 and 500 BC. Ayurvedic medicines or treatments have been used since ancient times for curing certain diseases, boosting immunity and for maintaining healthy life. Food is a source of all the energy and nutrients which are responsible for proper growth of body and proper functioning of body (Gaikwad et al., 2017). There is certain number of spices and herbs that has been used since ancient times for preventing or curing many diseases. That certain number of spices and herbs are having medicinal properties which benefits for the same. Spices and Herbs like Turmeric, Ginger, Garlic, Mint, Tulsi, Black Pepper and many more imparts highly medicinal properties that can help in prevention and curing of various diseases like Cardiovascular diseases(CVD), Diabetes, Cancer, Respiratory diseases etc.

Early information out from china about
COVID-19 is that some people are at higher risk of getting very sick from these diseases. This include

Older adults

People having lower immunity

People who have serious chronic medical conditions like Heart diseases, Diabetes and Lung diseases

So regarding this issue many researcher and scientist are trying to find or develop drug that can cure COVID-19. They have tested different drugs and combination of different drugs on COVID-19. But still there is no drug developed that can cure this diseases.

Ayurveda experts have suggested combination some spices and herbs like Giloy, Tulsi, Turmeric, Black Pepper and Ginger that can used as prevention and curing of COVID-19. This haven't yet proved clinically but by examine its medicinal properties, it is claimed that it may benefits in prevention and curing of COVID-19. Decoction ('Kadha') of this spices and herbs are to be made and consumed twice a day for good and effective result. The medicinal properties of all the above mentioned spices and herbs are shown in Table 2.

\section{Coronavirus cases}

There are currently 286,667confirmed cases and 11,888 deaths from the coronavirus COVID-19 outbreak as of March 21, 2020, 14:06 GMT (Source: www.worldmeters.info) (Fig. 2).

Coronavirus Cases: 286,667

Death: 11,888

Recovered: 93,602.

\section{Distribution of cases worldwide}

As it is showing in the chart other countries 
are having 205,688 cases and it conclude about $71.74 \%$ of total cases and the remaining 81,008 cases which is reported in china which conclude about $28.26 \%$ of total cases worldwide. The majority of confirmed cases are in China where COVID-19 originated (Data till March 21, 2020, 14:06 GMT Source: www.worldmeters.info).

Table.1 Types of human coronaviruses

\begin{tabular}{|l|l|l|l|}
\hline Virus & Location & Group & Year \\
\hline SARS & China & IV & 2003 \\
\hline NL63 & Netherland & I & 2004 \\
\hline NL & Netherland & I & 2004 \\
\hline HCoV-NH & New Haven,CT & I & 2005 \\
\hline HKU1 & Hong Kong & II & 2005 \\
\hline
\end{tabular}

Table.2 Medicinal benefits of spices and herbs

\begin{tabular}{|l|c|l|}
\hline Sr. No. & $\begin{array}{c}\text { Spices and } \\
\text { Herbs }\end{array}$ & \multicolumn{1}{|c|}{ Medicinal Benefits } \\
\hline 1. & Giloy & $\begin{array}{l}\text { Boost Immunity, Treats chronic fever, Improve digestion, treat } \\
\text { diabetes, Fight respiratory problems, Improve vision }\end{array}$ \\
\hline 2. & Tulsi & $\begin{array}{l}\text { Anti-Inflammatory, Stress Buster, Prevents heart diseases, } \\
\text { Respiratory Infections, Lowers Cholesterol }\end{array}$ \\
\hline 3. & Ginger & $\begin{array}{l}\text { Anti-Inflammatory, Lowers blood sugar, Lower cholesterol } \\
\text { level, Prevent cancer, Improve brain function }\end{array}$ \\
\hline 4. & Turmeric & $\begin{array}{l}\text { Increase antioxidant capacity, Improve brain function, Prevent } \\
\text { Cancer, Benefits against depression, Fight chronic diseases }\end{array}$ \\
\hline $\mathbf{5 .}$ & Black Pepper & $\begin{array}{l}\text { High in antioxidant, anti-inflammatory, Improve blood sugar, } \\
\text { Boost absorption of nutrients, lower cholesterol level }\end{array}$ \\
\hline
\end{tabular}

India COVID-19 coronavirus cases by State/UN

Table.3 Active and closed coronavirus cases (Source: www.worldmeters.info)

\begin{tabular}{|l|l|}
\hline Active Cases & Closed Cases \\
\hline $\begin{array}{l}\mathbf{1 8 1 , 1 7 7} \\
\text { Currently Infected Patients }\end{array}$ & $\begin{array}{l}105,490 \\
\text { Cases which had an outcome: }\end{array}$ \\
$\begin{array}{l}\mathbf{1 7 3 , 0 6 0}(\mathbf{9 6 \% )}) \\
\text { in Mild Condition }\end{array}$ & $\begin{array}{l}93,602(89 \%) \\
\text { Recovered / Discharged }\end{array}$ \\
$\begin{array}{l}\mathbf{8 , 1 1 7}(\mathbf{4 \%}) \\
\text { Serious or Critical }\end{array}$ & $11,888(11 \%)$ \\
\hline
\end{tabular}


Fig.1 Schematic labelled diagram of Coronavirus (SARS-CoV) (Peiris et al., 2004)

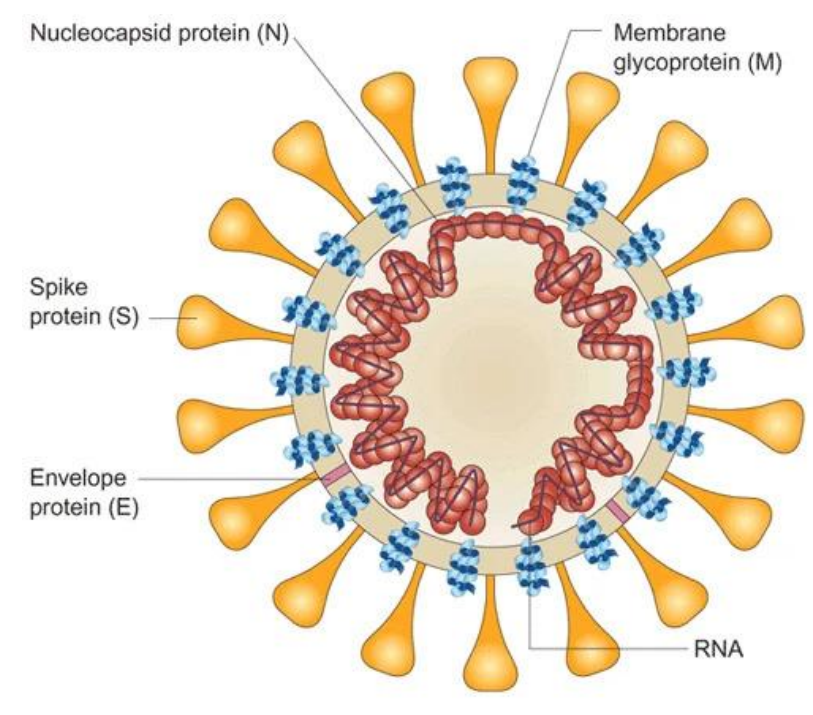

Fig.2 Coronavirus cases worldwide

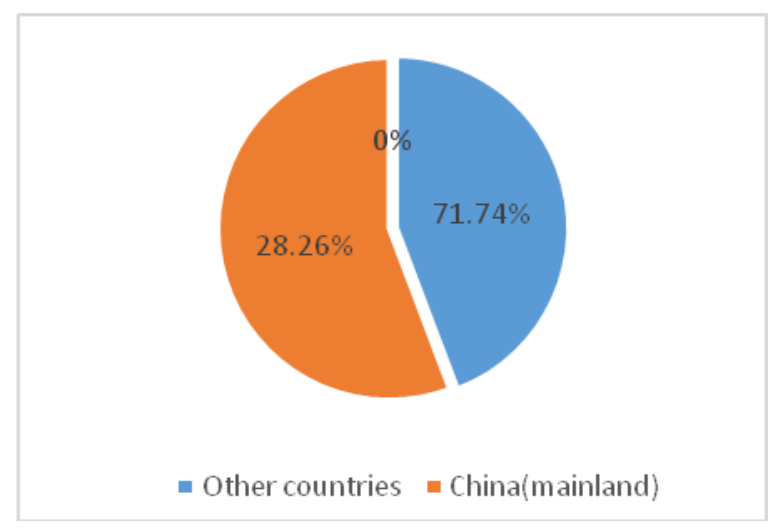

In conclusion, COVID-19 is acute respiratory disease which caused by coronavirus $(\mathrm{CoV})$. COVID-19 is showing quite similar symptoms as of influenza and swine-flu diseases but the genomic sequence or structure of this virus (coronavirus) is different than that of influenza and swine-flu. On 30 January 2020 World Health Organization (WHO) declared an international public health emergency due to outbreak of COVID-19. At present, about 1, 50,000 people got affected by COVID-19 and carry death rate of about 3\%. Despite the fact that the desire disease (COVID-19) is harmful but no antidote to treating this disease has been found yet. In this literature general information, symptoms, precaution, are covered. Apart from this many researchers and scientist are working to develop the vaccine that can effectively useful to cure COVID-19.

\section{References}

Eliza Barclay. The conspiracy theories about the origins of the coronavirus, debunked. March 12, 2020 https://www.vox.com/2020/3/4/21156 607/how-did-the-coronavirus-getstarted-china-wuhan-lab

Esper F, Kanwar A and Selvaraju S (2017). Human CoronavirusHKU1 Infection 
Among Adults in Cleveland, Ohio. Open Forum Infect Dis 4(2): ofx052. doi: 10.1093/ofid/ofx052

Esper F, Shapiro ED, Weibel C, Ferguson D, Landry ML, Kahn JS. Association between a novel human coronavirus and Kawasaki disease [see comment]. J Infect Dis. 2005; 191:499-502.

Fouchier RA, Hartwig NG, Bestebroer TM, et al., A previously undescribed coronavirus associated with respiratory disease in humans. Proc Natl Acad Sci USA. 2004; 101:62126216.

Peiris, J., Guan, Y. and Yuen, K. Severe acute respiratory syndrome. Nat Med 10, S88-S97 (2004). https://doi.org/10.1038/nm1143

Sarah Donovan. COVID-19 (SARS-CoV-2) Assay Tests. March 11, 2020. https://www.assaygenie.com/sarscov2 -covid19-detection-methods

Timesofindia.com. CORONAVIRUS: These books and movies PREDICTED the outbreak of deadly coronavirus years ago!! Times of India. March 4, 2020. https://timesofindia.indiatimes.com/lif e-style/health-fitness/healthnews/coronavirus-these-books-andmovies-predicted-the-outbreak-ofdeadly-coronavirus-years-ago-heresthe-completelist/articleshow/74475313.cms

Van der Hoek L, Pyrc K, Jebbink MF, Identification of a new human coronavirus. Nat Med. 2004; 10:368373.

www.who.inthttps://www.who.int/emergencie s/diseases/novel-coronavirus-2019 accessed on 21/03/2020

www.worldmeters.info https://www.worldometers.info/corona virus/coronavirus-cases/\#casedistribution

\section{How to cite this article:}

Tejas R. Suthar, Sandip T. Gaikwad and Abhinn D. Suthar. 2020. Severe Acute Respiratory Syndrome Coronavirus 2 (SARS-CoV-2) and Coronavirus Disease-2019 (COVID-19): A Review. Int.J.Curr.Microbiol.App.Sci. 9(04): 3201-3208. doi: https://doi.org/10.20546/ijcmas.2020.904.372 